\title{
Increasing access to family planning in Ghana through policy change: Task-sharing to enable auxiliary nurses to provide contraceptive implant services
}

Population Council

Follow this and additional works at: https://knowledgecommons.popcouncil.org/departments_sbsr-rh

Part of the Demography, Population, and Ecology Commons, Family, Life Course, and Society Commons, Health Policy Commons, International Public Health Commons, Maternal and Child Health Commons, and the Women's Health Commons How does access to this work benefit you? Let us know!

\section{Recommended Citation}

"Increasing access to family planning in Ghana through policy change: Task-sharing to enable auxiliary nurses to provide contraceptive implant services." Accra: Population Council, 2014. 

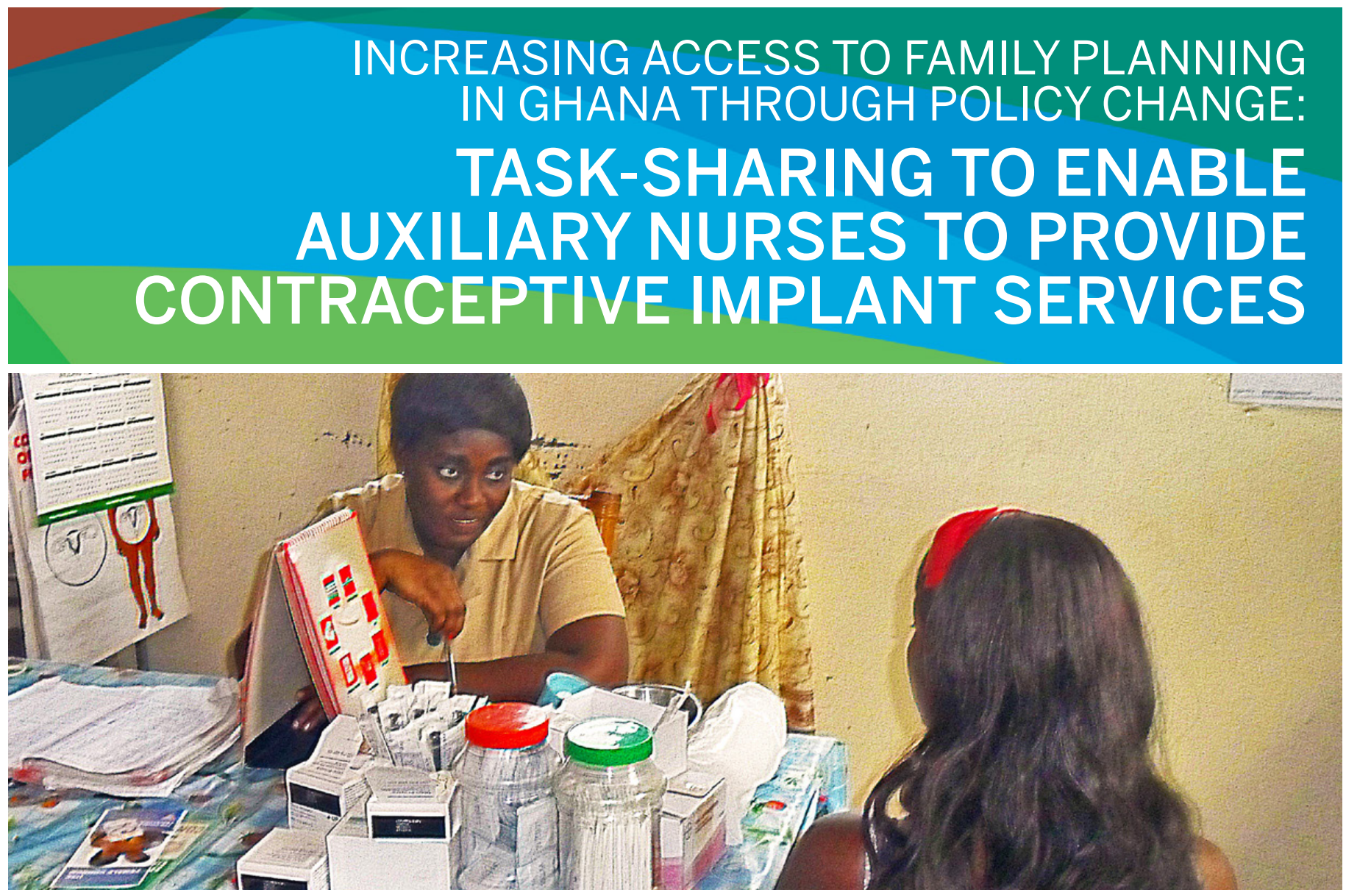

\section{WHY TASK-SHARING?}

Determining and establishing the optimal mix of health personnel is a major challenge for most health care organizations and health systems, according to the World Health Organization (WHO 2000). Health care is labor intensive and managers strive to identify a mix of staff that can safely deliver a range of services using available resources. In many developing countries, primary-level workers, auxiliary staff, and community health workers (CHWs) are being trained to assume roles and perform functions traditionally reserved for mid- or high-level cadres of health workers as a means of optimizing the number and capacity of available providers. The intention of this process, known as "tasksharing" or "task-shifting," is "to train cadres who do not normally have competencies for specific tasks to deliver them and thereby increase levels of health care access" (WHO 2012).

A more rational sharing of tasks and responsibilities among cadres of health workers is a promising strategy for improving access and cost-effectiveness within health systems. The World Health Organization recently undertook a rigorous review of research from around the world. Based on this evidence, WHO developed guidance on which key maternal and newborn health services can safely and effectively be delivered by, and shared between, cadres of health workers, including types of contraceptive methods.

\section{WHAT IS THE SITUATION IN GHANA?}

Ghana has made significant progress toward reducing the maternal mortality ratio (MMR) of 740 per 100,000 live births recorded in the 1990s to 350 per 100,000 live births in 2008 (WHO et al. 2010). This rate is still unacceptably high and more effort is needed if Ghana is to reach Millennium Development Goal 5: 185 deaths per 100,000 live births. Among the key strategies for reaching this target is increasing the contraceptive prevalence rate (CPR) and by so doing reducing unmet need for family planning. It is estimated that satisfying the unmet need for family planning alone could cut the number of maternal deaths by almost a third (WHO 2014).

Up to 26 percent of married Ghanaian women have an unmet need for family planning and one in four currently married women is using a modern contraceptive method (GSS 2011). One factor contributing to low usage of modern methods is a shortage of trained staff and particularly those skilled in providing effective long-acting reversible and permanent methods. The strength of the health-sector workforce having the
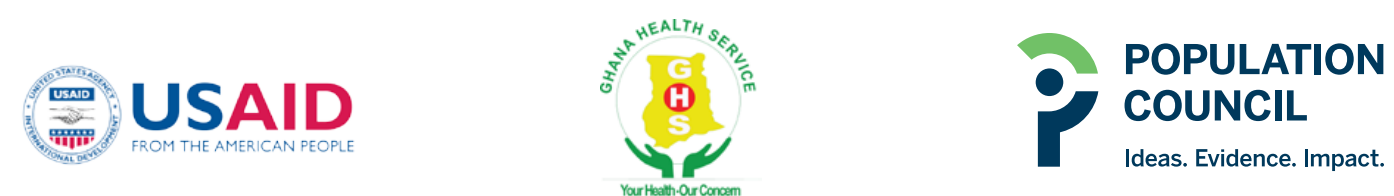
professional qualifications to provide these methods has progressively improved over the years but falls short of the WHO recommended number per population (GHS 2010).

Until recently, implant services were provided primarily by trained midwives. Currently, three implants are available in Ghana: Jadelle ${ }^{\circledR}$ (since 2007), Sino-implant II ${ }^{\circledR}$ (since 2012), and Implanon ${ }^{\circledR}$ (since 2012). Sino-implant $I^{\circledR}$, under the brand name Zarin, has been introduced in Marie Stopes International clinics and by other private health providers but is yet to be incorporated into the public health system. Various partners have supported GHS in updating midwives' skills to include implant insertion and removal. Lead trainers supported by Merck (for Implanon) and Bayer (for Jadelle) as well as EngenderHealth and UNFPA have collaborated with GHS to train service providers (mainly midwives) in contraceptive implant services. Introduction and scale up of these implants has been framed within a policy that allows midwives, but restricts the lower cadre of health workers, to insert and remove implants.

Community Health Nurses (CHNs) are the largest cadre of auxiliary nurses to provide communities with basic preventive health care and health education services. Their tasks under Ghana's Community-Based Health Planning and Services (CHPS) program include: the provision of quality health information; minor curative services; counseling on all contraceptive methods, including the lactational amenorrhea method (LAM); provision of pills, injectables, condoms, and emergency contraceptive pills; and referrals for IUDs, implants, and sterilization services. Although $\mathrm{CHNs}$ have not been allowed to provide implants, WHO's recent review of the evidence on the safety of implant insertion and removal concluded that auxiliary nurses could deliver implants under certain conditions (see "Who Recommendation" box). WHO's task-sharing guidance defines auxiliary nurses as having "some training in secondary school. A period of on-the-job training may be included, and sometimes formalized apprenticeships. An auxiliary nurse has basic nursing skills and no training in nursing

\section{WHO RECOMMENDATION}

We recommend the use of Auxiliary Nurses to deliver insertion and removal of contraceptive implant services with targeted monitoring and evaluation.

Recommend with targeted monitoring and evaluation: This rating indicates uncertainty about the effectiveness or acceptability of an intervention, especially with regard to particular contexts or conditions. Interventions classified as such can be considered for implementation (including at scale), provided they are accompanied by targeted monitoring and evaluation. Particular attention must be given to specific issues about which there are concerns (such as risks or harms) and for which little or no relevant information is available. Information about monitoring and evaluation may be obtained from a range of sources, including routine data and survey data.

(WHO 2012: 3)

decisionmaking. However, in different countries the level of training may vary between a few months and two to three years."

\section{WHAT HAVE WE ACCOMPLISHED?}

In 2008, the Population Council and partners American College of Nurses and Midwives, Centre for the Development of People, and EngenderHealth, through the USAID-funded CHPS Technical Assistance (CHPS-TA) project, collaborated with GHS to train a carefully selected group of $33 \mathrm{CHNs}$ in six regions of the country in the insertion and removal of Jadelle ${ }^{\circledR}$ to augment the services being provided by midwives. Prior to this training, CHNs were oriented toward community engagement and family planning counseling, which resulted in more clients opting for implant services. These clients were referred to facilities that had midwives on staff who could provide the service, and many were discouraged because of the long distances they would have to travel and the transportation costs they would incur to receive these services.

Ghana Health Service (GHS) offers a full range of family planning services, including provision of short-acting, long-acting, and permanent methods. Data from the 2011 Ghana Multiple Indicator Cluster Survey (MICS) indicate contraceptive prevalence among married women in Ghana as follows:

$\begin{array}{lllr}\text { Injectables } & 9 \% & \text { Female sterilization } & 2 \% \\ \text { Periodic abstinence } & 9 \% & \text { Lactational amenorrhea method (LAM) } & 2 \% \\ \text { Pill (oral contraceptive) } & 8 \% & \text { (Less than 1 percent use withdrawal, IUDs, male } \\ \text { Male condoms } & 3 \% & \text { sterilization, or vaginal contraceptive methods } \\ \text { Implants } & 3 \% & \text { [diaphragm, foam, jelly]). }\end{array}$


Under the Reducing Maternal Mortality and Morbidity (R3M) Program, which is funded by an anonymous donor and seeks to increase access to long-term family planning methods, EngenderHealth and the Population Council consulted and held advocacy meetings with the Family Health Division of GHS and other family planning stakeholders to consolidate support for permitting $\mathrm{CHNs}$ to provide implant services. EngenderHealth then collaborated with GHS to evaluate the competency levels of the $33 \mathrm{CHNs}$ trained through the CHPS-TA project.

The assessment found that knowledge of the technology was high, as were counseling, insertion, and removal skills, and more than 75 percent of the $\mathrm{CHNs}$ reported not experiencing any complications when providing the implant. The $33 \mathrm{CHNs}$ inserted 1,051 implants during the year preceding the assessment, with five CHNs having inserted more than 40 each. However, more than 80 percent of the $\mathrm{CHNs}$ and their managers indicated a need for further training in infection prevention, counseling, and management of side effects and complications, and more than two-thirds requested further training in insertion and removal. Moreover, the assessment recommended a review of the existing reproductive health policy and service delivery standards to permit and support appropriately trained $\mathrm{CHNs}$ in the provision of implant services. Support was overwhelming at all levels for such a policy review. In the words of one regional manager:

"For access to FP services and for FP coverage to improve, national policy on FP implants service delivery should be revised to include $\mathrm{CHNs}$ as part of the cadre delivering these services. Training on FP implants should be incorporated in their school curriculum" (Aboagye et al. 2011).

GHS, in collaboration with the Population Council, subsequently convened a series of stakeholder meetings to discuss experiences with training this small group of $\mathrm{CHNs}$, the findings of the assessment, the WHO tasksharing recommendations, and the results from a case study that documented the role of $\mathrm{CHNs}$ as family planning (FP) service providers within the CHPS program (Ntsua et al. 2011).

As a result of this process, GHS announced on February 14, 2013 that the reproductive health policy would be changed to allow $\mathrm{CHNs}$ to provide implant services effective immediately. Official letters were issued to all regional health directorates notifying them of the policy change.

\section{WHAT PROCESSES CONTRIBUTED TO THE POLICY CHANGE?}

To summarize, the key actions and enabling environment elements that led to the policy change were:

- The Ghana Demographic and Health Survey 2008, the Ghana Multiple Indicator Cluster Survey 2011, and other surveys showed increased uptake in contraceptive implants among clients preferring long-acting reversible FP methods (GSS, GHS, and ICF Macro 2009; GSS 2011).

- Use of implants significantly increased between 2008 and 2012. Acceptors for implants in GHS facilities increased from 25,603 in 2008 to 65,119 in 2012, whereas the percentage contribution to acceptor increased from 1.4 percent to 3.7 percent in the same period.

- Provider shortages led district health management teams to request an exception to the policy so they could train $\mathrm{CHNs}$ to provide implant services.

- Continuous advocacy was targeted to influence the Ministry of Health (MOH) and Ghana Health Service (GHS) to remove policy restrictions thereby allowing task-sharing to increase the number of providers able to provide implants.

- Training and follow-up assessment of a small number of CHNs demonstrated feasibility and safety for CHNs to undertake insertion and removal.

- Evidence regarding provision of implants by auxiliary nurses in other developing countries was systematically reviewed and shared.

- This evidence was used to support a WHOendorsed recommendation for task-sharing among auxiliary nurses globally with targeted monitoring and evaluation.

- A coordinated series of meetings was held with a wide range of stakeholders to consider the implications of a policy change and the rollout of a tasksharing strategy.

- Policy review process and recommended change was accepted by senior decisionmakers at the $\mathrm{MOH}$ and GHS.

- Official memorandum announcing policy change was issued and distributed immediately throughout the public health system.

- Next steps needed to operationalize policy and systems modifications identified, planned, and budgeted. 


\section{POLICY HAS CHANGED, SO WHAT'S NEXT?}

To enable this policy change to take effect, the following activities have been planned and budgeted:

- Review of the "Sub-dermal Contraceptive Implant" training and monitoring manuals for trainees (midwives and $\mathrm{CHNs}$ ) and trainers to ensure that specific guidelines are available for provision of the three contraceptive implants (Implanon, Jadelle, and Zarin).

- GHS will review and update the national RH/FP service policy standards and protocols to incorporate the new policy.

- The Nurses and Midwives Council will revise the community health training school preservice curriculum to include Implanon, Jadelle, and Zarin implant insertion and removal training.

- GHS will train and certify up to 4,000 CHNs nationwide by the year 2015 with a grant from the European Union through the Millennium Accelerated Framework Fund.

- GHS, in collaboration with the Population Council, will routinely undertake targeted monitoring and evaluation of trained $\mathrm{CHNs}$ as recommended by WHO, to assess competency skills in the provision of contraceptive implant services.

\section{REFERENCES}

Aboagye, Patrick, Irene Sawerty, Nickolas Kanlisi, Eunice Agyei, and Joseph Akolgo. 2011. Assessment of the Performance of Community Health Nurses Trained to Provide Contraceptive Implants Services. Accra: EngenderHealth.

Ghana Health Service (GHS). 2010. The Health Sector in Ghana, Facts and Figures. Accra.

Ghana Statistical Service (GSS). 2011. Ghana Multiple Indicator Cluster Survey with an Enhanced Malaria Module and Biomarker, 2011. Accra.

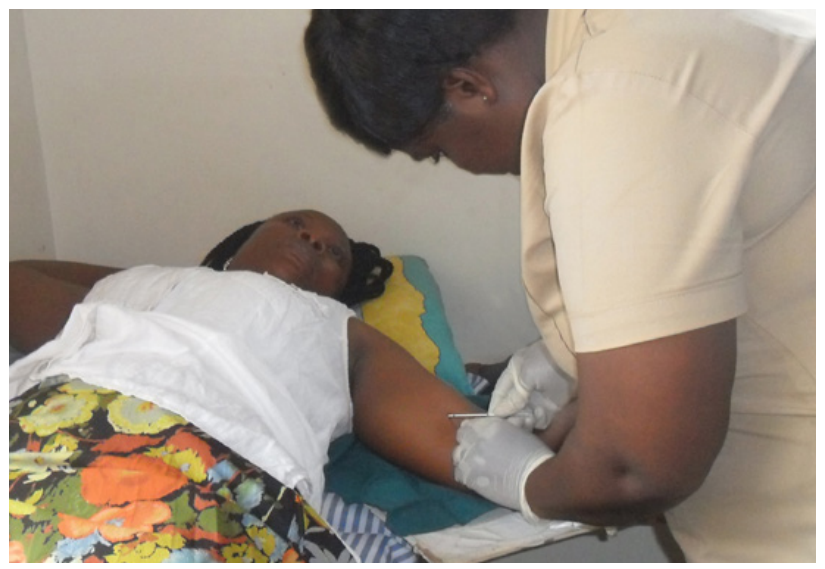

Community Health Nurses (CHNs) are the largest cadre of auxiliary nurses to provide communities with basic preventive health care and health education services. The $\mathrm{CHN}$ above has been trained both in the insertion and removal of a contraceptive implant.

Ghana Statistical Service (GSS), Ghana Health Service (GHS), and ICF Macro. 2009. Ghana Demographic and Health Survey 2008. Accra: GSS, GHS, and ICF Macro.

Ntsua, Stephen, Placide Tapsoba, Gloria Quansah Asare, and Frank Nyonator. 2011. Repositioning Community-Based Family Planning in Ghana: A Case Study of the Community-Based Health Planning and Services (CHPS). Accra: Population Council.

World Health Organization (WHO). 2000. The World Health Report 2000-Health Systems: Improving Performance. Geneva.

. 2012. WHO Recommendations: Optimizing Health Worker Roles to Improve Access to Key Maternal and Newborn Health Interventions Through Task Shifting. Geneva.

__. 2014. “MDG5: Improve Maternal Health.” http:// www.who.int/topics/millennium_development_goals/ maternal_health/en/

World Health Organization (WHO), UNICEF, UNFPA, and World Bank. 2010. Trends in Maternal Mortality 1990 to 2008. Geneva: WHO.

\section{For more information, contact:}

DR. PLACIDE TAPSOBA

Population Council

14b Ridge Road, Roman Ridge

Accra, Ghana

Tel: (+233) (0) 302780 711/2

Fax: (+233) (0) 302780713

email: info.ghana@popcouncil.org
DR. PATRICK K. ABOAGYE

Family Health Division

Ghana Health Service

Tel: (+233) (0) 302666101

The Population Council confronts critical health and development issues-from stopping the spread of HIV to improving reproductive health and ensuring that young people lead full and productive lives. Through biomedical, social science, and public health research in 50 countries, we work with our partners to deliver solutions that lead to more effective policies, programs, and technologies that improve lives around the world. Established in 1952 and headquartered in New York, the Council is a nongovernmental, nonprofit organization governed by an international board of trustees. 